\title{
Banxia Baizhu Tianma Decoction for Essential Hypertension: A Systematic Review of Randomized Controlled Trials
}

\author{
Xingjiang Xiong, ${ }^{1}$ Xiaochen Yang, ${ }^{1}$ Wei Liu, ${ }^{1}$ Bo Feng, ${ }^{1}$ Jizheng Ma, ${ }^{2}$ \\ Xinliang Du, ${ }^{3}$ Pengqian Wang, ${ }^{4}$ Fuyong Chu, ${ }^{5}$ Jun Li, ${ }^{1}$ and Jie Wang ${ }^{1}$ \\ ${ }^{1}$ Department of Cardiology, Guang' anmen Hospital, China Academy of Chinese Medical Sciences, Beixiange 5, \\ Xicheng District, Beijing 100053, China \\ ${ }^{2}$ Department of Gastroenterology, Guang' anmen Hospital, China Academy of Chinese Medical Sciences, Beijing 100053, China \\ ${ }^{3}$ Graduate School, China Academy of Chinese Medical Sciences, Beijing 100700, China \\ ${ }^{4}$ Department of Endocrinology, Traditional Chinese Medicine Hospital of Mentougou District, Beijing 102300, China \\ ${ }^{5}$ Department of Cardiology, Traditional Chinese Medicine Hospital of Beijing, Beijing 100010, China
}

Correspondence should be addressed to Xingjiang Xiong, 5administration@163.com and Jie Wang, wangjie0103@yahoo.cn

Received 23 August 2012; Revised 16 November 2012; Accepted 22 November 2012

Academic Editor: MyeongSoo Lee

Copyright ( $) 2012$ Xingjiang Xiong et al. This is an open access article distributed under the Creative Commons Attribution License, which permits unrestricted use, distribution, and reproduction in any medium, provided the original work is properly cited.

\begin{abstract}
Objectives. To assess the current clinical evidence of Banxia Baizhu Tianma Decoction (BBTD) for essential hypertension (EH). Search Strategy. Electronic databases were searched until July 2012. Inclusion Criteria. We included randomized clinical trials testing BBTD against placebo, antihypertensive drugs, or combined with antihypertensive drugs against antihypertensive drugs. Data Extraction and Analyses. Study selection, data extraction, quality assessment, and data analyses were conducted according to Cochrane standards. Results. 16 randomized trials were included. Methodological quality of the included trials was evaluated as generally low. 2 trials compared prescriptions based on BBTD using alone with antihypertensive drugs. Meta-analysis showed no significant effect of modified BBTD compared with captopril in systolic blood pressure (MD: $-0.75(-5.77,4.27) ; P=0.77)$ and diastolic blood pressure (MD: $-0.75(-2.89,1.39) ; P=0.49) .14$ trials compared the combination of BBTD or modified BBTD plus antihypertensive drugs with antihypertensive drugs. Meta-analysis showed there are significant beneficial effect on systolic blood pressure in the combination group compare to the antihypertensive drugs (MD: $-4.33(-8.44,-0.22) ; P=0.04)$. The safety of BBTD is uncertain. Conclusions. There is encouraging evidence of BBTD for lowering SBP, but evidence remains weak. Rigorously designed trials are warranted to confirm these results.
\end{abstract}

\section{Introduction}

Hypertension is an increasingly important medical and public health issue, which could lead to severe complications [1]. High blood pressure is a major, independent risk factor for cardiovascular disease (CVD). The relationship between blood pressure (BP) and risk of CVD events is continuous, consistent, and independent of other risk factors. The higher the BP, the greater is the chance of heart attack, heart failure, stroke, and kidney diseases. The prevention and management of hypertension are major public health challenges. Much of hypertension, cardiovascular, and cerebrovascular diseases would be preventable if the rise in BP with age could be prevented or diminished [2].
Complementary and alternative medicine (CAM) is becoming increasingly popular and frequently used among patients with CVD [3-7]. Approximately 50\% of US residents use some form of alternative medicine; $10 \%$ use it for their children [8]. Recent researches showed that CAM (also integrative medicine) could contribute to blood pressure control [9-12]. Chinese medicine (CM) [13, 14], including herbal medicine, acupuncture, moxibustion, and cupping Tai chi and Qigong, as one of the most important parts in CAM, is thought to be effective for the treatment of essential hypertension [15-18]. It has been considered as an effective adjunct treatment by either physicians or patients in China. More and more patients firstly select the combination 
therapy, just CM combined with antihypertensive drugs, for better efficacy both in BP and clinical symptom such as headache, neck and shoulder pain, dizziness, and fatigue. For seeking the best evidence of CM in making decisions for hypertensive patients, an increasing number of systematic reviews (SR) and meta-analysis have been conducted to assess the efficiency of CM for hypertension [19-24]. It is found out that CM could contribute to lower BP smoothly, recover the circadian rhythm of $\mathrm{BP}$, and improve symptoms and signs especially [25]. And the efficacy of CM for treating hypertension is suggested by a large number of published case series and randomized trials [26, 27], although some trials have demonstrated negative results $[28,29]$. Mechanistic studies have demonstrated that the antihypertensive effect is related to activation of endothelial nitric oxide synthase (eNOS) and inducible nitric oxide synthase (iNOS) $[30,31]$, regulation of vascular endothelium function [26, $32]$, inhibiting proliferation of adventitial fibroblasts and collagen synthesis [33], inhibition of vascular smooth muscle cell proliferation [34], and so forth. A series of Chinese herbs have been authorized recommended by the Chinese government in Pharmacopoeia of the People's Republic of China (2010 edition).

Banxia baizhu tianma decoction (BBTD), containing eight commonly used herbs (Pinellia ternata, atractylodes macrocephala, Gastrodia elata, tangerine peel, poria cocos, Glycyrrhiza, ginger, and red jujube), is a classical Chinese herbal formula noted in Medical Revelations in Qing dynasty. It has been widely used to treat hypertension-related symptoms in clinical practice for centuries in China [25]. The most common symptoms include headache, dizziness, nausea, and vomiting, which belong to the liver yang hyperactivity and fluid retention syndrome [25]. The mechanism of the prescription maybe calming liver, suppressing liver yang hyperactivity, dissipating excessive fluid, and expelling phlegm according to the theory of TCM. Recently, modern researches showed that BBTD have potential effect of lowing $\mathrm{BP}$ in vitro and in vivo [25, 35-38]. Biochemically, BBTD also showed good effect in improving the mesenteric endothelial dysfunction and the hemodynamic parameters, inhibiting the expression of nitric oxide (NO) and interleukin-1 (IL-1), decreasing serum levels of total cholesterol (TC), triglycerides (TGs), and low-density lipoprotein-cholesterol (LDL-C), regulating rennin-angiotensin system (RAS), and improving the oxidative stress state, so as to lower the arterial pressure [35-38].

Currently, BBTD used alone or combined with antihypertensive drugs has been widely used as an alternative and effective method for the treatment of essential hypertension in China. And until now a number of clinical studies of BBTD reported the clinical effect ranging from case reports and case series to controlled observational studies and randomized clinical trials. However, there is no critically appraised evidence such as systematic reviews or meta analyses on potential benefits and harms of BBTD for essential hypertension to justify their clinical use and their recommendation. This paper aims to assess the current clinical evidence of BBTD for essential hypertension.

\section{Methods}

2.1. Database and Search Strategies. Literature searches were conducted in Chinese National Knowledge Infrastructure (CNKI), Chinese Scientific Journal Database (VIP), Chinese Biomedical Literature Database (CBM), PubMed, EMBASE, and the Cochrane Central Register of Controlled Trials (CENTRAL) in the Cochrane Library (July 2012). We also searched the reference list of retrieved papers. Databases in Chinese were searched to retrieve the maximum possible number of trials of BBTD for essential hypertension because BBTD is mainly used and researched in China. All of those searches ended on 3 July, 2012. Ongoing registered clinical trials were searched in the website of Chinese clinical trial registry (http://www.chictr.org/) and international clinical trial registry by US National Institutes of Health (http://clinicaltrials.gov/). The following search terms were used individually or combined: "hypertension," "essential hypertension," "banxia baizhu tianma decoction," "clinical trial," and "randomized controlled trial." The bibliographies of included studies were searched for additional references.

2.2. Inclusion Criteria. All the parallel randomized controlled trials (RCTs) of all the prescriptions based on "banxia baizhu tianma decoction" compared with antihypertensive drugs in patients with hypertension were included. RCTs combined banxia baizhu tianma decoction with antihypertensive drugs compared with antihypertensive drugs and all the modified banxia baizhu tianma decoction were included as well. According to the principle of the similarity of traditional Chinese medicine (TCM) formula [39], the number of modified herbs should not be more than 4 , so that to ensure the similarity is greater than or equal to 0.5 . And the key herbs in the modified banxia baizhu tianma decoction should include Pinellia ternata, atractylodes macrocephala, Gastrodia elata, and poria cocos, according to the theory of TCM. There were no restrictions on population characteristics, language and publication type. The main outcome measure was blood pressure. Duplicated publications reporting the same groups of participants were excluded.

2.3. Data Extraction and Quality Assessment. Two authors conducted the literature searching (Xiong and Yang), study selection (Xiong and Wang), and data extraction (Xiong and Li) independently. The extracted data included authors, title of study, year of publication, study size, age and sex of the participants, details of methodological information, name and component of Chinese herbs, treatment process, details of the control interventions, outcomes, and adverse effects for each study. Disagreement was resolved by discussion and reached consensus through a third party (J. Wang).

The methodological quality of trials was assessed independently using criteria from the Cochrane Handbook for Systematic Review of Interventions, Version 5.1.0 (Xiong and Yang) [56]. The items included random sequence generation (selection bias), allocation concealment (selection bias), blinding of participants and personnel (performance bias), blinding of outcome assessment (detection bias), incomplete 


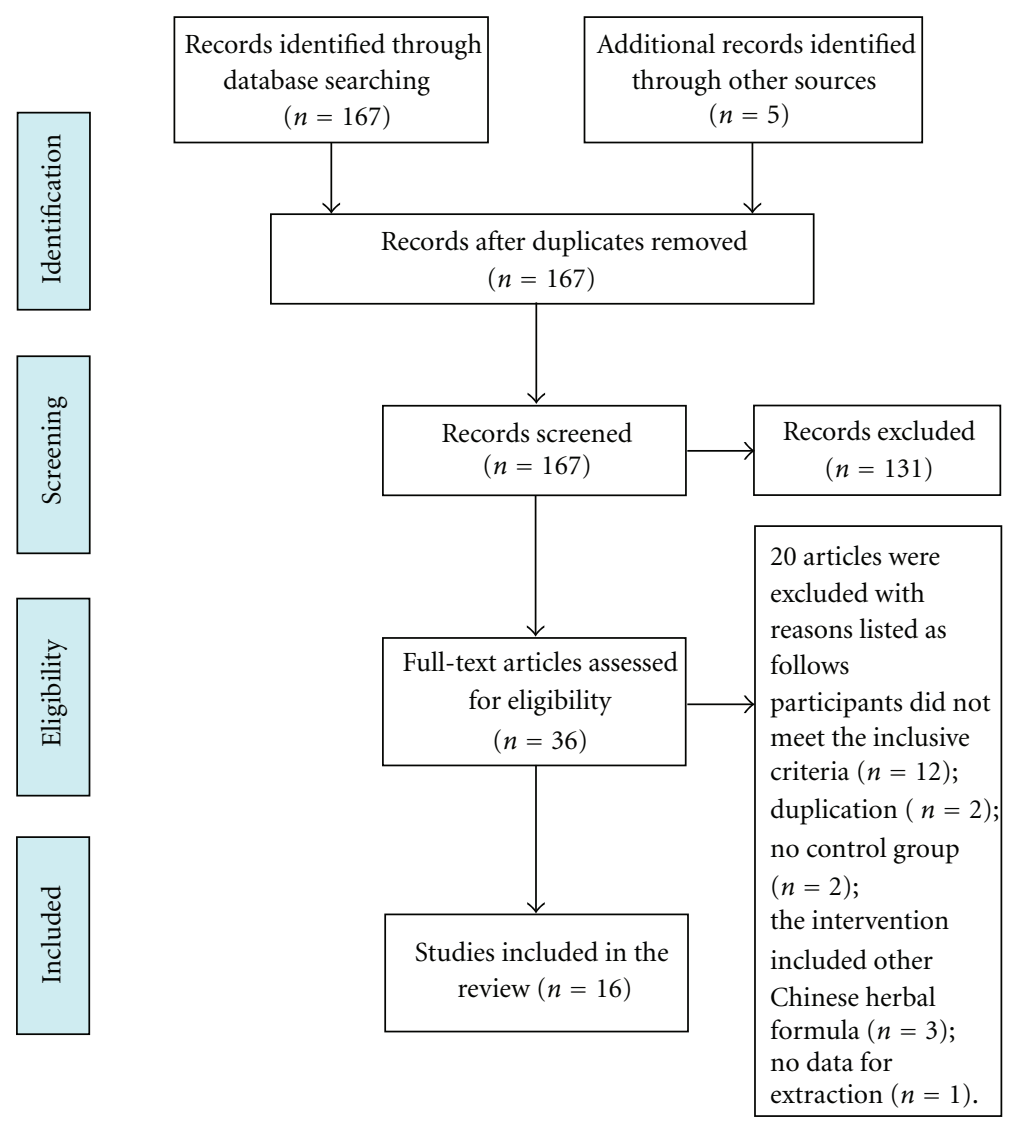

FIgURE 1: PRISMA 2009 flow diagram.

outcome data (attrition bias), selective reporting (reporting bias), and other bias. The quality of all the included trials was categorized to low/unclear/high risk of bias ("yes" for a low of bias, "no" for a high risk of bias, "unclear" otherwise). Then trials were categorized into three levels: low risk of bias (all the items were in low risk of bias), high risk of bias (at least one item was in high risk of bias), unclear risk of bias (at least one item was in unclear).

2.4. Data Synthesis. RevMan 5.1 software provided by the Cochrane Collaboration was used for data analyses. Continuous outcome will be presented as mean difference (MD) and its $95 \%$ CI. Heterogeneity was recognized significant when $I^{2} \geq 50 \%$. Fixed-effects model was used if there is no significant heterogeneity of the data; random-effects model was used if significant heterogeneity existed $\left(50 \%<I^{2}<\right.$ $85 \%)$. Publication bias would be explored by funnel plot analysis if sufficient studies were found.

\section{Result}

3.1. Description of Included Trials. A flow chart depicted the search process and study selection (as shown in Figure 1). After primary searches from the databases, 167 articles were screened. After reading the titles and abstracts, 131 articles of them were excluded. Full texts of 36 articles were retrieved, and 20 articles were excluded with reasons listed as follows: participants did not meet the inclusive criteria $(n=12)$, duplication $(n=2)$, no control group $(n=2)$, the intervention included other Chinese herbal formula $(n=3)$, and no data for extraction $(n=1)$. In the end, 16 RCTs [4055] were included. All the RCTs were conducted in China and published in Chinese. The characteristics of included trials were listed in Table 1.

1424 patients with essential hypertension were included. There was a wide variation in the age of subjects (1978 years). Sixteen (16) trials specified five diagnostic criteria of hypertension, five trials $[40,41,45,50,52]$ used Chinese Guidelines for the Management of Hypertension2005 (CGMH-2005), five trials [43, 44, 49, 53, 55] used 1999 WHO-ISH guidelines for the management of hypertension (1999 WHO-ISH GMH), two trials [46, 47] used China Guidelines on Prevention and Management of High Blood Pressure-2004 (CGPMHBP-2004), one trial [51] used Chinese Guidelines for the Management of Hypertension1999 (CGMH-1999), one trial [51] used the Sixth Report of the Joint National Committee on Prevention, Detection, Evaluation, and Treatment of High Blood Pressure (JNCVI), and two trials $[42,48]$ only demonstrated patients with essential hypertension. Sixteen (16) trials specified three diagnostic criteria of abundant phlegm-dampness syndrome in TCM, nine trials $[41,45,46,49-53,55]$ used Guidelines of Clinical Research of New Drugs of Traditional Chinese 


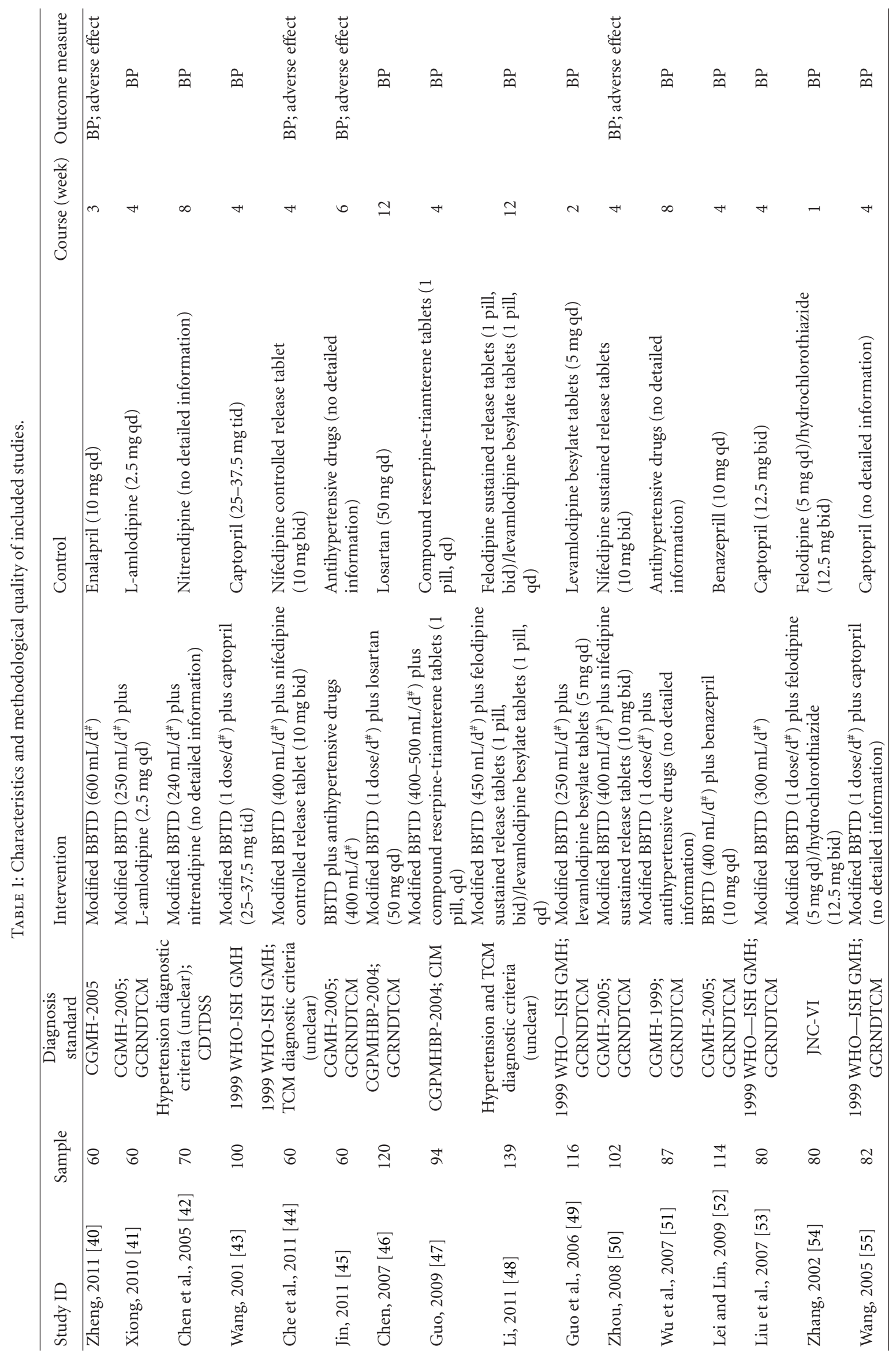


TABLE 2: Composition of formula.

\begin{tabular}{|c|c|c|}
\hline Study ID & Formula & Composition of formula \\
\hline Zheng, 2011 [40] & Modified BBTD & $\begin{array}{l}\text { Pinellia ternate } 9 \mathrm{~g} \text {, atractylodes macrocephala } 15 \mathrm{~g} \text {, Gastrodia elata } 10 \mathrm{~g} \text {, tangerine peel } 10 \mathrm{~g} \text {, } \\
\text { poria cocos } 10 \mathrm{~g}, \text { Glycyrrhiza } 4 \mathrm{~g} \text {, ginger } 2 \text { pieces, red jujube } 5 \text {, grass leaved sweetflag } 10 \mathrm{~g} \text {, } \\
\text { ligusticum chuanxiong hort } 9 \mathrm{~g} \text {, alisma orientalis } 15 \mathrm{~g} \text {, and Grifola umbellata } 10 \mathrm{~g}\end{array}$ \\
\hline Xiong, 2010 [41] & Modified BBTD & $\begin{array}{l}\text { Pinellia ternate } 12 \mathrm{~g} \text {, atractylodes macrocephala } 15 \mathrm{~g} \text {, Gastrodia elata } 15 \mathrm{~g} \text {, tangerine peel } \\
12 \mathrm{~g} \text {, poria cocos } 12 \mathrm{~g} \text {, alisma orientalis } 15 \mathrm{~g} \text {, plantain seed } 15 \mathrm{~g} \text {, bamboo bark } 9 \mathrm{~g} \text {, villous } \\
\text { amomum fruit } 3 \mathrm{~g} \text {, Pinellia pedatisecta Schott } 12 \mathrm{~g} \text {, grass leaved sweetflag } 15 \mathrm{~g} \text {, ginger } 9 \mathrm{~g} \text {, } \\
\text { red jujube 5, and Glycyrrhiza } 6 \mathrm{~g}\end{array}$ \\
\hline Chen et al., 2005 [42] & Modified BBTD & $\begin{array}{l}\text { Pinellia ternate } 6 \mathrm{~g} \text {, Gastrodia elata } 9 \mathrm{~g} \text {, atractylodes macrocephala } 9 \mathrm{~g} \text {, poria cocos } 12 \mathrm{~g} \text {, } \\
\text { tangerine peel } 12 \mathrm{~g} \text {, Pinellia pedatisecta Schott } 12 \mathrm{~g} \text {, fructus aurantii } 12 \mathrm{~g} \text {, Glycyrrhiza } 6 \mathrm{~g}\end{array}$ \\
\hline Wang, 2001 [43] & Modified BBTD & $\begin{array}{l}\text { Pinellia ternate } 15 \mathrm{~g} \text {, atractylodes macrocephala } 12 \mathrm{~g} \text {, Gastrodia elata } 15 \mathrm{~g} \text {, tangerine peel } \\
12 \mathrm{~g} \text {, poria cocos } 12 \mathrm{~g} \text {, alisma orientalis } 15 \mathrm{~g} \text {, Uncaria } 15 \mathrm{~g} \text { (put in later), abalone shell } 15 \mathrm{~g} \\
\text { (decocting first), ginger } 15 \mathrm{~g} \text {, jujube 5, and Glycyrrhiza } 6 \mathrm{~g}\end{array}$ \\
\hline Che et al., 2011 [44] & Modified BBTD & $\begin{array}{l}\text { Pinellia ternate } 15 \mathrm{~g} \text {, atractylodes macrocephala } 25 \mathrm{~g} \text {, Gastrodia elata } 10 \mathrm{~g} \text {, tangerine peel } \\
10 \mathrm{~g} \text {, poria cocos } 10 \mathrm{~g} \text {, kudzu root } 10 \mathrm{~g} \text {, Sophora flower } 15 \mathrm{~g} \text {, cassia seed } 10 \mathrm{~g} \text {, hawthorn } 15 \mathrm{~g} \text {, } \\
\text { and Glycyrrhiza } 5 \mathrm{~g}\end{array}$ \\
\hline Jin, $2011[45]$ & BBTD & $\begin{array}{l}\text { Pinellia ternate } 10 \mathrm{~g} \text {, atractylodes macrocephala } 10 \mathrm{~g} \text {, Gastrodia elata } 10 \mathrm{~g} \text {, tangerine peel } \\
10 \mathrm{~g} \text {, poria cocos } 15 \mathrm{~g} \text {, Glycyrrhiza } 5 \mathrm{~g} \text {, ginger } 10 \mathrm{~g} \text {, and jujube } 10 \mathrm{~g}\end{array}$ \\
\hline Chen, 2007 [46] & Modified BBTD & $\begin{array}{l}\text { Pinellia ternate } 9 \mathrm{~g} \text {, atractylodes macrocephala } 12 \mathrm{~g} \text {, Gastrodia elata } 6 \mathrm{~g} \text {, tangerine peel } 10 \mathrm{~g} \text {, } \\
\text { poria cocos } 15 \mathrm{~g} \text {, alisma orientalis } 10 \mathrm{~g} \text {, hawthorn } 10 \mathrm{~g} \text {, cassia seed } 15 \mathrm{~g} \text {, grass leaved } \\
\text { sweetflag } 6 \mathrm{~g} \text {, ligusticum chuanxiong hort } 6 \mathrm{~g} \text {, Salvia miltiorrhiza } 12 \mathrm{~g} \text {, and Glycyrrhiza } 5 \mathrm{~g}\end{array}$ \\
\hline Guo, 2009 [47] & Modified BBTD & $\begin{array}{l}\text { Pinellia ternate } 12 \mathrm{~g} \text {, atractylodes macrocephala } 15 \mathrm{~g} \text {, Gastrodia elata } 10 \mathrm{~g} \text {, tangerine peel } 9 \mathrm{~g} \text {, } \\
\text { poria cocos } 10 \mathrm{~g} \text {, ligusticum chuanxiong hort } 10 \mathrm{~g} \text {, officinal magnolia bark } 6-10 \mathrm{~g} \text {, } \\
\text { chrysoidine } 9 \mathrm{~g} \text {, grass leaved sweetflag } 10 \mathrm{~g} \text {, curcuma longa } 10 \mathrm{~g} \text {, ginger } 3 \text { pieces, and jujube } 3\end{array}$ \\
\hline $\mathrm{Li}, 2011[48]$ & Modified BBTD & $\begin{array}{l}\text { Pinellia ternate } 10 \mathrm{~g} \text {, atractylodes macrocephala } 10 \mathrm{~g} \text {, Gastrodia elata } 10 \mathrm{~g} \text {, tangerine peel } \\
12 \mathrm{~g} \text {, poria cocos } 15 \mathrm{~g} \text {, citrus aurantium } 10 \mathrm{~g} \text {, bamboo bark } 10 \mathrm{~g} \text {, and Glycyrrhiza } 6 \mathrm{~g}\end{array}$ \\
\hline Guo et al., 2006 [49] & Modified BBTD & $\begin{array}{l}\text { Pinellia ternate } 18 \mathrm{~g} \text {, atractylodes macrocephala } 12 \mathrm{~g} \text {, Gastrodia elata } 18 \mathrm{~g} \text {, tangerine peel } \\
12 \mathrm{~g} \text {, poria cocos } 15 \mathrm{~g} \text {, grass leaved sweetflag } 15 \mathrm{~g} \text {, Eucommia ulmoides Oliv. } 15 \mathrm{~g} \text {, Prunella } \\
\text { vulgaris } 12 \mathrm{~g} \text {, Glycyrrhiza } 6 \mathrm{~g} \text {, and jujube } 5\end{array}$ \\
\hline Zhou, 2008 [50] & Modified BBTD & $\begin{array}{l}\text { Pinellia ternate } 12 \mathrm{~g} \text {, atractylodes macrocephala } 12 \mathrm{~g} \text {, Gastrodia elata } 6 \mathrm{~g} \text {, tangerine peel } 9 \mathrm{~g} \text {, } \\
\text { poria cocos } 12 \mathrm{~g} \text {, bamboo bark } 9 \mathrm{~g} \text {, Glycyrrhiza } 6 \mathrm{~g} \text {, villous amomum fruit } 3 \mathrm{~g} \text {, ginger } 3 \mathrm{~g} \text {, } \\
\text { and jujube } 5\end{array}$ \\
\hline Wu et al., 2007 [51] & Modified BBTD & $\begin{array}{l}\text { Pinellia ternate } 10 \mathrm{~g} \text {, atractylodes macrocephala } 10 \mathrm{~g} \text {, Gastrodia elata } 10 \mathrm{~g} \text {, tangerine peel } 10 \\
\mathrm{~g} \text {, poria cocos } 15 \mathrm{~g} \text {, bamboo bark } 10 \mathrm{~g} \text {, Coix lacryma-jobi } 20 \mathrm{~g} \text {, Glycyrrhiza } 3 \mathrm{~g} \text {, and ginger } 3 \\
\text { pieces }\end{array}$ \\
\hline Lei and Lin, 2009 [52] & BBTD & $\begin{array}{l}\text { Pinellia ternate } 12 \mathrm{~g} \text {, atractylodes macrocephala } 12 \mathrm{~g} \text {, Gastrodia elata } 15 \mathrm{~g} \text {, tangerine peel } 9 \mathrm{~g} \text {, } \\
\text { poria cocos } 12 \mathrm{~g}, \text { Glycyrrhiza } 6 \mathrm{~g} \text {, ginger } 3 \mathrm{~g} \text {, and jujube } 5\end{array}$ \\
\hline Liu et al., 2007 [53] & Modified BBTD & $\begin{array}{l}\text { Pinellia ternate } 9 \mathrm{~g} \text {, atractylodes macrocephala } 15 \mathrm{~g} \text {, Gastrodia elata } 6 \mathrm{~g} \text {, tangerine peel } 6 \mathrm{~g} \text {, } \\
\text { poria cocos } 6 \mathrm{~g} \text {, Glycyrrhiza } 5 \mathrm{~g} \text {, angelica sinensis } 10 \mathrm{~g} \text {, white peony root } 10 \mathrm{~g} \text {, lotus leaf } 15 \mathrm{~g} \text {, } \\
\text { and alisma orientalis } 15 \mathrm{~g}\end{array}$ \\
\hline Zhang, 2002 [54] & Modified BBTD & $\begin{array}{l}\text { Pinellia ternate } 15 \mathrm{~g} \text {, atractylodes macrocephala } 15 \mathrm{~g} \text {, Gastrodia elata } 12 \mathrm{~g} \text {, tangerine peel } \\
12 \mathrm{~g} \text {, poria cocos } 12 \mathrm{~g} \text {, Glycyrrhiza } 10 \mathrm{~g} \text {, plantain seed } 15 \mathrm{~g} \text {, and Loranthus parasiticus } 15 \mathrm{~g}\end{array}$ \\
\hline Wang, 2005 [55] & Modified BBTD & $\begin{array}{l}\text { Pinellia ternate } 10 \mathrm{~g} \text {, atractylodes macrocephala } 15 \mathrm{~g} \text {, Gastrodia elata } 15 \mathrm{~g} \text {, tangerine peel } \\
15 \mathrm{~g} \text {, poria cocos } 30 \mathrm{~g} \text {, hawthorn } 15 \mathrm{~g} \text {, and grass leaved sweetflag } 15 \mathrm{~g}\end{array}$ \\
\hline
\end{tabular}

Medicine (GCRNDTCM), one trial [42] used Convention of Diagnosis and Treatment of Disease and Syndrome in Shanghai (CDTDSS), one trial [47] used Chinese internal medicine (CIM), two trials $[44,48]$ only demonstrated patients with abundant phlegm-dampness syndrome in TCM, and three trials $[40,43,54]$ did not report any TCM diagnostic criteria.

Interventions included all the prescriptions based on "banxia baizhu tianma decoction" alone, or combined with antihypertensive drugs. The controls included antihypertensive drugs alone. Two trials investigated the prescriptions based on "banxia baizhu tianma decoction" used alone [40, 53 ] versus antihypertensive drugs, and the rest fourteen trials [41-52, 54, 55] compared the prescriptions based on "banxia baizhu tianma decoction" plus antihypertensive drugs versus antihypertensive drugs.

The total treatment duration ranged from 7 days to 3 months. The variable prescriptions are presented in Table 1. 
TABLE 3: Quality assessment of included randomized controlled trials.

\begin{tabular}{|c|c|c|c|c|c|c|c|c|}
\hline Included trials & $\begin{array}{l}\text { Random } \\
\text { sequence } \\
\text { generation }\end{array}$ & $\begin{array}{c}\text { Allocation } \\
\text { concealment }\end{array}$ & $\begin{array}{c}\text { Blinding of } \\
\text { participants and } \\
\text { personnel }\end{array}$ & $\begin{array}{l}\text { Blinding of } \\
\text { outcome } \\
\text { assessment }\end{array}$ & $\begin{array}{c}\text { Incomplete } \\
\text { outcome } \\
\text { data }\end{array}$ & $\begin{array}{l}\text { Selective } \\
\text { reporting }\end{array}$ & $\begin{array}{c}\text { Other sources } \\
\text { of bias }\end{array}$ & $\begin{array}{c}\text { Risk of } \\
\text { bias }\end{array}$ \\
\hline Zheng, 2011 [40] & $\begin{array}{c}\text { Table of random } \\
\text { number }\end{array}$ & Unclear & Unclear & Unclear & No & No & Unclear & Unclear \\
\hline Xiong, 2010 [41] & Unclear & Unclear & Unclear & Unclear & Yes & No & Unclear & High \\
\hline Chen et al., 2005 [42] & Unclear & Unclear & Unclear & Unclear & Yes & No & Unclear & High \\
\hline Wang, 2001 [43] & Unclear & Unclear & Unclear & Unclear & Yes & No & Unclear & High \\
\hline Che et al., 2011 [44] & $\begin{array}{c}\text { Table of random } \\
\text { number }\end{array}$ & Unclear & Unclear & Unclear & No & No & Unclear & Unclear \\
\hline Jin, $2011[45]$ & Unclear & Unclear & Unclear & Unclear & No & No & Unclear & High \\
\hline Chen, 2007 [46] & $\begin{array}{c}\text { Table of random } \\
\text { number }\end{array}$ & Unclear & Unclear & Unclear & Yes & No & Unclear & Unclear \\
\hline Guo, 2009 [47] & Unclear & Unclear & Unclear & Unclear & Yes & No & Unclear & High \\
\hline Li, $2011[48]$ & Drawing & Unclear & Unclear & Unclear & Yes & No & Unclear & Unclear \\
\hline Guo et al., 2006 [49] & Unclear & Unclear & Unclear & Unclear & Yes & No & Unclear & High \\
\hline Zhou, 2008 [50] & Unclear & Unclear & Unclear & Unclear & No & No & Unclear & High \\
\hline Wu et al., 2007 [51] & Unclear & Unclear & Unclear & Unclear & Yes & No & Unclear & High \\
\hline Lei and Lin, 2009 [52] & Unclear & Unclear & Unclear & Unclear & Yes & No & Unclear & High \\
\hline Liu et al., 2007 [53] & Unclear & Unclear & Unclear & Unclear & Yes & No & Unclear & High \\
\hline Zhang, 2002 [54] & $\begin{array}{c}\text { Table of random } \\
\text { number }\end{array}$ & Unclear & Unclear & Unclear & Yes & No & Unclear & High \\
\hline Wang, 2005 [55] & Unclear & Unclear & Unclear & Unclear & Yes & No & Unclear & High \\
\hline
\end{tabular}

TABLE 4: Analyses of systolic blood pressure.

\begin{tabular}{|c|c|c|c|}
\hline Trials & & $\operatorname{MD}(95 \% \mathrm{CI})$ & $P$ value \\
\hline \multicolumn{4}{|l|}{ BBTD versus antihypertensive drugs } \\
\hline Modified BBTD versus captopril & 1 & $-0.75(-5.77,4.27)$ & 0.77 \\
\hline Meta-analysis & 1 & $-0.75(-5.77,4.27)$ & 0.77 \\
\hline \multicolumn{4}{|l|}{ BBTD plus antihypertensive drugs versus antihypertensive drugs } \\
\hline Modified BBTD plus L-amlodipine versus L-amlodipine & 1 & $-0.13(-4.93,4.67)$ & 0.96 \\
\hline Modified BBTD plus losartan versus losartan & 1 & $-7.38(-9.95,-4.81)$ & $<0.00001$ \\
\hline Modified BBTD plus antihypertensive drugs versus antihypertensive drugs & 1 & $-4.31(-8.39,-0.23)$ & 0.04 \\
\hline Meta-analysis & 3 & $-4.33(-8.44,-0.22)$ & 0.04 \\
\hline
\end{tabular}

The different compositions of Chinese herbal formula BBTD are presented in Table 2. All of the 16 trials used the BP as the outcome measure. Adverse effect was described in detail.

3.2. Methodological Quality of Included Trials. The majority of the included trials were assessed to be of general poor methodological quality according to the predefined quality assessment criteria (Table 3 ). The randomized allocation of participants was mentioned in all trials; however, only 5 trials stated the methods for sequence generation including random number table [40, 44, 46, 54] and drawing [48]. Insufficient information was provided to judge whether or not it was conducted properly. Allocation concealment, blinding of participants and personnel, and blinding of outcome assessment were not mentioned in all trials. None of trials reported dropout or withdraw. None of trials had a pretrial estimation of sample size. All the trials did not mention followup. We tried to contact the author for further information; however, no information has been provided to date.

\subsection{Effect of the Interventions}

3.3.1. "Banxia Baizhu Tianma Decoction" versus Antihypertensive Drugs (Western Medicine). Two trials [40, 53] compared prescriptions based on BBTD used alone with antihypertensive drugs. A change in blood pressure was reported in all the two RCTs $[40,53]$. One trial [53] showed the homogeneity in the consistency of the trial results. Thus, fixed-effects model should be used for statistical analysis. The meta-analysis showed no significant effect of modified BBTD compared with captopril alone in systolic blood pressure (MD: $-0.75(-5.77,4.27) ; P=0.77)$ and diastolic blood pressure (MD: $-0.75(-2.89,1.39) ; P=0.49)$ (Tables 4 and 5). 
TABLE 5: Analyses of diastolic blood pressure.

\begin{tabular}{lccc}
\hline Trials & & MD $(95 \%$ CI $)$ & $P$ value \\
\hline BBTD versus antihypertensive drugs & & & \\
$\quad$ Modified BBTD versus captopril & 1 & $-0.75(-2.89,1.39)$ & 0.49 \\
\hline Meta-analysis & 1 & $-0.75(-2.89,1.39)$ & 0.49 \\
\hline BBTD plus antihypertensive drugs versus antihypertensive drugs & & & \\
$\quad$ Modified BBTD plus L-amlodipine versus L-amlodipine & 1 & $1.55(-2.39,5.49)$ & 0.44 \\
Modified BBTD plus losartan versus losartan & 1 & $-3.85(-5.70,-2.00)$ & $<0.0001$ \\
$\quad$ Modified BBTD plus antihypertensive drugs versus antihypertensive drugs & 1 & $-1.24(-4.04,1.56)$ & 0.39 \\
\hline Meta-analysis & 3 & $-1.57(-4.54,1.40)$ & 0.30 \\
\hline
\end{tabular}

3.3.2. "Banxia Baizhu Tianma Decoction" Plus Antihypertensive Drugs versus Antihypertensive Drugs. Fourteen trials $[41-52,54,55]$ compared the combination of BBTD or modified BBTD plus antihypertensive drugs with antihypertensive drugs. A change in blood pressure was reported in all the included RCTs.

Systolic Blood Pressure (SBP). The 3 independent trials [41, $46,51]$ did not show homogeneity in the trial results, chisquare $=7.18,(P=0.03) ; I^{2}=72 \%$. Thus, random-effects model should be used for statistical analysis. The metaanalysis showed that there are significant beneficial effect on the combination group compared to the antihypertensive drugs used alone (MD: $-4.33(-8.44,-0.22) ; P=0.04)$ (Table 4).

Diastolic Blood Pressure (DBP). Three trials $[41,46,51]$ did not show homogeneity in the trial results, chi-square $=6.87$, $(P=0.03) ; I^{2}=71 \%$. Thus, random-effects model should be used for statistical analysis. The meta-analysis showed that there are no significant beneficial effect on the combination group compare to the antihypertensive drugs used alone (MD: $-1.57(-4.54,1.40) ; P=0.30)$ (Table 5).

3.4. Publication Bias. The number of trials was too small to conduct any sufficient additional analysis of publication bias.

3.5. Adverse Effect. Four out of sixteen trials mentioned the adverse effect $[40,44,45,50]$. Four trials reported five specific symptoms including headache, distending feeling in head, palpitations, drowsiness, and fatigue. Among them, no adverse events were found in two trials $[44,45]$. One trial reported adverse effect in enalapril group including headache, palpitations, drowsiness, and fatigue [40]. One trial mentioned adverse effect both in modified BBTD plus nifedipine sustained release tablets group and nifedipine sustained release tablets group including distending feeling in head [50].

\section{Discussion}

Based on the paper and meta-analyses of the outcome on either SBP or DBP, BBTD may have positive effects for lowing BP. BBTD as an adjunctive treatment to antihypertensive drugs significantly lowered SBP in patients with hypertension. However, according to potential publication bias and low-quality trials, available data are not adequate to draw a definite conclusion of BBTD for essential hypertension. And the positive findings should be interpreted conservatively.

Several limitations should be considered before accepting the findings of this paper. First, the quality of the included RCTs is generally low. Sixteen trials included in this paper had risk of bias in terms of design, reporting, and methodology. They provided only inadequate reporting of study design, allocation sequence, allocation concealment, blinding, intention to treat analysis, and dropouts account in the majority of trials. Randomization was mentioned but without further details, which do not allow a proper judgment of the conduct of the trials. All the trials did not describe the blinding in details. It directly led to performance bias and detection bias due to patients and researchers being aware of the therapeutic interventions for the subjective outcome measures. All the sixteen RCTs prohibited us to perform meaningful sensitivity analysis. All the included trials were not multicenter, large-scale RCTs. If poorly designed, all the trials would show larger differences compared with well designed trials.

Second, all the sixteen trials did not report the adverse effect of banxia baizhu tianma decoction. Therefore, a conclusion about the safety of BBTD cannot be made clearly. In China, it is widely believed that it is safe to use herbal medicines for various diseases. With more and more reports of adverse effects of Chinese herbal medicines, the safety of Chinese herbs and formulae needs to be monitored rigorously and reported appropriately in the future clinical trials.

Third, Vickers et al. demonstrated that some countries, for example, China, generate virtually no "negative" studies at all [57]. In other words, publication and other biases may play an important role. We only identified and included trials published in Chinese after conducting comprehensive searches. Most of the trials are small sample with positive findings. We tried to avoid language bias and location bias, but we cannot exclude potential publication bias.

Fourth, it is pointed out that, lacking Chinese medicine (CM) pattern criteria (also called syndrome or zheng) become the key issue both for RCT and clinical practice [5860]. For example, receiving CM or conventional therapies in patients with the same disease respectively, conventional treatment tends to produce a better curative effect than $\mathrm{CM}$ 
[61-64]. This should be the major reason why the RCTs failed to evaluate the real efficacy of CM. In this systematic review, three out of the sixteen trials $[40,43,54]$ did not report the TCM diagnostic criteria. Two trials $[44,48]$ reported the TCM diagnostic criteria but without further details. Therefore, further clinical trials should be conducted with clear TCM diagnostic criteria.

In conclusion, there is some encouraging evidence of BBTD for lowering SBP, but the evidence remains weak due to poor methodological quality of including studies. Rigorously designed trials seem to be warranted to confirm the results.

\section{Conflict of Interests}

All authors declare that they have no conflict of interests.

\section{Authors' Contribution}

X. Xiong, X. Yang, W. Liu, J. Ma, X. Du, P. Wang, F. Chu, and J. Li contributed equally to this paper.

\section{Acknowledgments}

The current work was partially supported by the National Basic Research Program of China (973 Program, no. 2003CB517103) and the National Natural Science Foundation Project of China (no. 90209011). The funders had no role in study design, data collection and analysis, decision to publish, or preparation of the paper.

\section{References}

[1] A. V. Chobanian, G. L. Bakris, H. R. Black et al., "Seventh report of the joint national committee on prevention, detection, evaluation, and treatment of high blood pressure," Hypertension, vol. 42, no. 6, pp. 1206-1252, 2003.

[2] T. Krause, K. Lovibond, M. Caulfield, T. McCormack, B. Williams, and Guideline Development Group, "Management of hypertension: summary of NICE guidance," British Medical Journal, vol. 343, Article ID d4891, 2011.

[3] K. J. Chen, K. K. Hui, M. S. Lee, and H. Xu, "The potential benefit of complementary/alternative medicine in cardiovascular diseases," Evidence-Based Complementary and Alternative Medicine, vol. 2012, Article ID 125029, 1 pages, 2012.

[4] D. J. Su and L. F. Li, "Trends in the use of complementary and alternative medicine in the United States: 2002-2007," Journal of Health Care For the Poor and Underserved, vol. 22, pp. 295309, 2011.

[5] C. Hawk, H. Ndetan, and M. W. Evans, "Potential role of complementary and alternative health care providers in chronic disease prevention and health promotion: an analysis of National Health Interview Survey data," Preventive Medicine, vol. 54, pp. 18-22, 2012.

[6] $\mathrm{H} . \mathrm{Xu}$ and $\mathrm{K}$. Chen, "Integrative medicine: the experience from China," Journal of Alternative and Complementary Medicine, vol. 14, no. 1, pp. 3-7, 2008.

[7] H. Xu and K. J. Chen, "Integrating traditional medicine with biomedicine towards a patient-centered healthcare system,"
Chinese Journal of Integrative Medicine, vol. 17, no. 2, pp. 8384, 2011.

[8] C. S. Moyer, "Weighing alternative remedies," February, 2012, amednews.com, http://www.ama-assn.org/amednews/2012/ 02/20/prsa0220.htm.

[9] A. B. Luiz, I. Cordovil, J. Barbosa Filho, and A. S. A. Ferreira, "Zangfu zheng (patterns) are associated with clinical manifestations of zang shang (target-organ damage) in arterial hypertension," Chinese Medicine, vol. 6, p. 23, 2011.

[10] R. Nahas, "Complementary and alternative medicine approaches to blood pressure reduction: an evidence-based review," Canadian Family Physician, vol. 54, no. 11, pp. 1529-1533, 2008.

[11] E. Ernst, "Complementary/alternative medicine for hypertension: a mini-review," Wiener Medizinische Wochenschrift, vol. 123, pp. 386-391, 2005.

[12] J. Wang and X. J. Xiong, "Current situation and perspectives of clinical study in integrative medicine in China," EvidenceBased Complementary and Alternative Medicine, vol. 2012, Article ID 268542, 11 pages, 2012.

[13] J. Wang, P. Q. Wang, and X. J. Xiong, "Current situation and re-understanding of syndrome and formula syndrome in Chinese medicine," Internal Medicine. In press.

[14] H. Xu and K. J. Chen, "Making evidence-based decisions in the clinical practice of integrative medicine," Chinese Journal of Integrative Medicine, vol. 16, no. 6, pp. 483-485, 2010.

[15] K. J. Chen and H. Xu, "The integration of traditional Chinese medicine and Western medicine," European Review, vol. 11, no. 2, pp. 225-235, 2003.

[16] H. Xu and K. J. Chen, "Complementary and alternative medicine: is it possible to be mainstream?" Chinese Journal of Integrative Medicine, vol. 18, no. 6, pp. 403-404, 2012.

[17] M. S. Lee, H. J. Lim, and M. S. Lee, "Impact of qigong exercise on self-efficacy and other cognitive perceptual variables in patients with essential hypertension," Journal of Alternative and Complementary Medicine, vol. 10, no. 4, pp. 675-680, 2004.

[18] M. S. Lee, M. S. Lee, E. S. Choi, and H. T. Chung, "Effects of Qigong on blood pressure, blood pressure determinants and ventilatory function in middle-aged patients with essential hypertension," American Journal of Chinese Medicine, vol. 31, no. 3, pp. 489-497, 2003.

[19] M. S. Lee, M. H. Pittler, R. E. Taylor-Piliae, and E. Ernst, "Tai chi for cardiovascular disease and its risk factors: a systematic review," Journal of Hypertension, vol. 25, no. 9, pp. 1974-1975, 2007.

[20] J. I. Kim, J. Y. Choi, H. Lee, M. S. Lee, and E. Ernst, "Moxibustion for hypertension: a systematic review," BMC Cardiovascular Disorders, vol. 10, article 33, 2010.

[21] M. S. Lee, T. Y. Choi, B. C. Shin, J. I. Kim, and S. S. Nam, "Cupping for hypertension: a systematic review," Clinical and Experimental Hypertension, vol. 32, no. 7, pp. 423-425, 2010.

[22] M. S. Lee, M. H. Pittler, R. Guo, and E. Ernst, "Qigong for hypertension: a systematic review of randomized clinical trials," Journal of Hypertension, vol. 25, no. 8, pp. 1525-1532, 2007.

[23] M. S. Lee, E. N. Lee, J. I. Kim, and E. Ernst, "Tai chi for lowering resting blood pressure in the elderly: a systematic review," Journal of Evaluation in Clinical Practice, vol. 16, no. 4, pp. 818-824, 2010.

[24] J. Wang, K. W. Yao, X. C. Yang et al., "Chinese patent medicine liu wei di huang wan combined with antihypertensive drugs, a new integrative medicine therapy, for the treatment of essential hypertension: a systematic review of randomized 
controlled trials," Evidence-Based Complementary and Alternative Medicine, vol. 2012, Article ID 714805, 7 pages, 2012.

[25] J. Wang and X. J. Xiong, "Control strategy on hypertension in Chinese medicine," Evidence-Based Complementary and Alternative Medicine, vol. 2012, Article ID 284847, 6 pages, 2012.

[26] G. W. Zhong, M. J. Chen, Y. H. Luo et al., "Effect of Chinese herbal medicine for calming Gan and suppressing hyperactive yang on arterial elasticity function and circadian rhythm of blood pressure in patients with essential hypertension," Chinese Journal of Integrative Medicine, vol. 17, no. 6, pp. 414420, 2011.

[27] H. Li, L. T. Liu, W. M. Zhao et al., "Effect of traditional and integrative regimens on quality of life and early renal impairment in elderly patients with isolated systolic hypertension," Chinese Journal of Integrative Medicine, vol. 16, no. 3, pp. 216221, 2010.

[28] E. A. Macklin, P. M. Wayne, L. A. Kalish et al., "Stop Hypertension with the Acupuncture Research Program (SHARP): results of a randomized, controlled clinical trial," Hypertension, vol. 48, no. 5, pp. 838-845, 2006.

[29] J. J. Li, Z. L. Lu, W. R. Kou et al., "Long-term effects of xuezhikang on blood pressure in hypertensive patients with previous myocardial infarction: data from the Chinese coronary secondary prevention study (CCSPS)," Clinical and Experimental Hypertension, vol. 32, no. 8, pp. 491-498, 2010.

[30] D. D. Kim, F. A. Sanchez, R. G. Duran, T. Kanetaka, and W. N. Duran, "Endothelial nitric oxide synthase is a molecular vascular target for the Chinese herb Danshen in hypertension," American Journal of Physiology, vol. 292, pp. H2131-H2137, 2007.

[31] D. D. Kim, A. M. Pica, R. G. Durán, and W. N. Durán, "Acupuncture reduces experimental renovascular hypertension through mechanisms involving nitric oxide synthases," Microcirculation, vol. 13, no. 7, pp. 577-585, 2006.

[32] C. F. Ng, C. M. Koona, D. W. S. Cheung et al., "The anti-hypertensive effect of Danshen (Salvia miltiorrhiza) and Gegen (Pueraria lobata) formula in rats and its underlying mechanisms of vasorelaxation," Journal of Ethnopharmacology, vol. 137, pp. 1366-1372, 2011.

[33] M. Ren, J. Zhang, B. Wang et al., "Qindan-capsule inhibits proliferation of adventitial fibroblasts and collagen synthesis," Journal of Ethnopharmacology, vol. 129, no. 1, pp. 53-58, 2010.

[34] S. Wang, Y. Chen, D. He et al., "Inhibition of vascular smooth muscle cell proliferation by serum from rats treated orally with Gastrodia and Uncaria decoction, a traditional Chinese formulation," Journal of Ethnopharmacology, vol. 114, no. 3, pp. 458-462, 2007.

[35] J. Y. Jiang, X. Z. Wang, S. S. Luo, X. Wang, K. Bian, and Y. Yan, "Effect of Banxia baizhu tianma decoction on the left ventricular hypertrophy of hypertrophied myocardium in spontaneously hypertensive rat," Zhongguo Zhong Xi Yi Jie He Za Zhi, vol. 30, no. 10, pp. 1061-1066, 2010.

[36] X. Z. Wang, J. Y. Jiang, S. S. Luo et al., "Effect of Banxia bai$z$ hu tianma decoction on the vascular endothelial function of spontaneous hypertensive rats," Zhongguo Zhong Xi Yi Jie He Za Zhi, vol. 31, no. 6, pp. 811-815, 2011.

[37] M. Q. Zhang, "Effect of modified Banxia baizhu tianma decoction on 38 cases of elderly patients with hypertension," Shiyong Zhong Xi Yi Jie He Lin Chuang, vol. 10, no. 2, pp. 19-20, 2010.

[38] Q. F. Wu, M. X. Wen, and D. H. Lan, "Effects of Banxia baizhu tianma decoction on salt sensitivity and blood lipid in hypertensive patients with abundant phlegm-dampness syndrome," Fujian Yi Yao Za Zhi, vol. 29, no. 1, pp. 146-148, 2007.
[39] Y. B. Li, M. Cui, Y. Yang et al., "Similarity of traditional Chinese medicine formula," Zhong Hua Zhong Yi Yao Xue Kan, vol. 30, no. 5, pp. 1096-1097, 2012.

[40] M. J. Zheng, "Effect of Banxia baizhu tianma decoction on 30 patients with hypertension," Zhongguo Zhong Yi Yao Xian Dai Yuan Cheng Jiao Yu, vol. 9, no. 14, p. 33, 2011.

[41] Y. W. Xiong, "Clinical effect of the modified Banxia baizhu tianma decoction combining western medicine on 60 patients with phlegm-dampness type primary hypertension," Zhongguo Zhong Yi Yao Xian Dai Yuan Cheng Jiao Yu, vol. 8, no. 13, pp. 67-68, 2010.

[42] L. Q. Chen, H. F. Yu, and W. Z. Wang, "Report of hypertension treated with Banxia baizhu tianma decoction and western medicine," Gansu Zhong Yi, vol. 18, no. 2, pp. 1-3, 2005.

[43] J. T. Wang, "Effects of modified Banxia baizhu tianma decoction and captopril on essential hypertension with abundant phlegm-dampness syndrome," Zhongguo Zhong Yi Ji Zhen, vol. 10 , no. 6, p. 364, 2001.

[44] Q. F. Che, L. J. He, and J. Y. Xu, "Clinical effect of the modified Banxia baizhu tianma decoction on homocysteine in essential hypertension with abundant phlegm-dampness syndrome," Liaoning Zhong Yi Za Zhi, vol. 1813-1814, no. 9, pp. 1-3, 2011.

[45] Z. X. Jin, "Clinical effect of Banxia baizhu tianma decoction on essential hypertension with abundant phlegm-dampness syndrome and blood uric acid metabolism," Xin Zhong Yi, vol. 43, no. 11, pp. 5-6, 2011.

[46] L. Q. Chen, "The effects of Banxia baizhu tianma decoction and Zexie Decoction on bodymass index and depressurization of patient with hypertension type of accumulation of phlegmdamp in TCM," Zhongguo Zhong Yi Ji Zhen, vol. 16, no. 6, pp. 650-651, 2007.

[47] X. H. Guo, "Clinical effect of the modified Banxia baizhu tianma decoction on 48 patients with phlegm-dampness type hypertension," Hebei Zhong Yi, vol. 31, no. 6, pp. 870-871, 2009.

[48] B. H. Li, "Clinical effect of Wen Dan Decoction and Banxia baizhu tianma decoction on 73 patients with hypertension," Zhong Xi Yi Jie He Xin Nao Xue Guan Bing Za Zhi, vol. 9, no. 8, p. 910, 2011.

[49] S. P. Guo, X. P. He, X. M. Lin, and H. Zhu, "Effect of the modified Banxia baizhu tianma decoction on 60 patients with phlegm-dampness type primary hypertension," Shanxi Zhong Yi, vol. 27, no. 7, pp. 797-798, 2006.

[50] H. M. Zhou, "Clinical effect of the modified Banxia baizhu tianma decoction on hypertension with abundant phlegmdampness syndrome," Beijing Zhong Yi Yao, vol. 27, no. 5, pp. 363-365, 2008.

[51] Q. F. Wu, M. X. Wen, and D. H. Lan, "Effect of Banxia baizhu tianma decoction on insulin resistance and blood lipid in hypertensive patients with abundant phlegm-dampness syndrome," Fujian Zhong Yi Xue Yuan Xue Bao, vol. 17, no. 2, pp. 8-10, 2007.

[52] Z. Y. Lei and X. Lin, "Effect of Banxia baizhu tianma decoction on blood pressure variability of menopausal patients with hypertension," Xian Dai Zhong Xi Yi Ji He Za Zhi, vol. 18, no. 5, pp. 499-500, 2009.

[53] Y. P. Liu, M. L. Hu, H. T. Zhang, and Y. S. Shen, "Clinical effect of the modified Banxia baizhu tianma decoction on middleaged primary hypertension," Zhong Yi Yao Xin Xi, vol. 24, no. 1, pp. 27-28, 2007.

[54] Z. Z. Zhang, "Clinical effect of the modified Banxia baizhu tianma decoction on isolated systolic hypertension," Liaoning Zhong Yi Za Zhi, vol. 29, no. 1, p. 31, 2002. 
[55] S. X. Wang, "Clinical effect of treating hypertension from spleen," Zhong Yi Yao Xue Kan, vol. 23, no. 11, p. 2100, 2005.

[56] J. P. T. Higgins and S. Green, Cochrane Handbook For Systematic Reviews of Interventions, Version 5. 1. 0, The Cochrane Collaboration, 2009.

[57] A. Vickers, N. Goyal, R. Harland, and R. Rees, "Do certain countries produce only positiveresults? A systematic review of controlled trials," Controlled Clinical Trials, vol. 19, no. 2, pp. 159-166, 1998.

[58] K. J. Chen, "Clinical service of Chinese medicine," Chinese Journal of Integrative Medicine, vol. 14, no. 3, pp. 163-164, 2008.

[59] K. J. Chen and L. Z. Li, "Study of traditional Chinese medicine-which is after all the right way?" Chinese Journal of Integrative Medicine, vol. 11, no. 4, pp. 241-242, 2005.

[60] K. J. Chen, "Where are we going?" Chinese Journal of Integrative Medicine, vol. 16, no. 2, pp. 100-101, 2010.

[61] N. Robinson, "Integrative medicine-traditional Chinese medicine, a model?" Chinese Journal of Integrative Medicine, vol. 17, no. 1, pp. 21-25, 2011.

[62] A. P. Lu and K. J. Chen, "Chinese medicine pattern diagnosis could lead to innovation in medical sciences," Chinese Journal of Integrative Medicine, vol. 17, no. 11, pp. 811-817, 2011.

[63] A. P. Lu and K. J. Chen, "Integrative medicine in clinical practice: from pattern differentiation in traditional Chinese medicine to disease treatment," Chinese Journal of Integrative Medicine, vol. 15, no. 2, p. 152, 2009.

[64] M. Y. Liu and K. J. Chen, "Convergence: the tradition and the modern," Chinese Journal of Integrative Medicine, vol. 18, no. 3, pp. 164-165, 2012. 


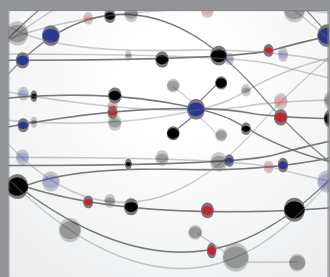

The Scientific World Journal
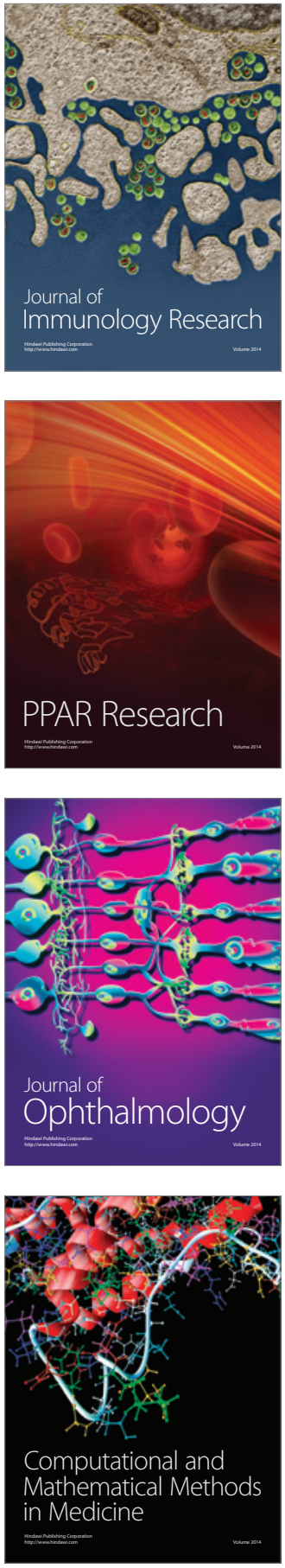

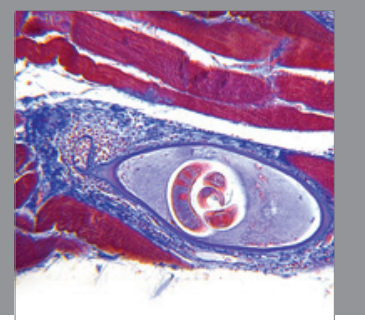

Gastroenterology

Research and Practice
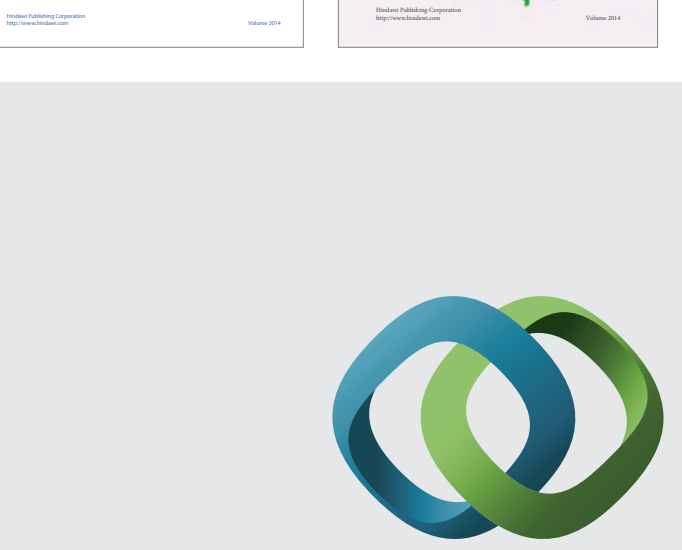

\section{Hindawi}

Submit your manuscripts at

http://www.hindawi.com
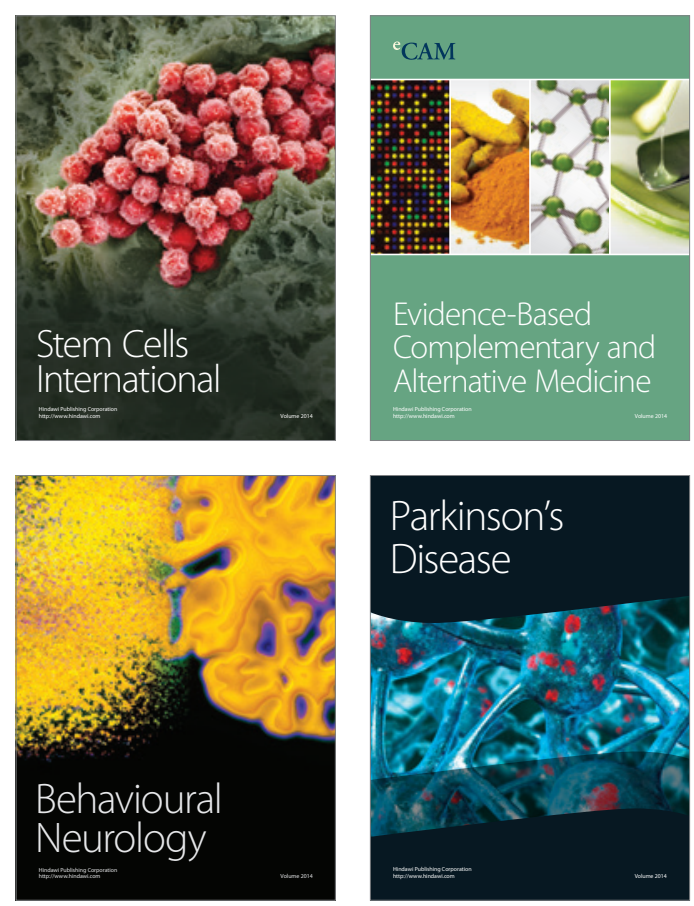

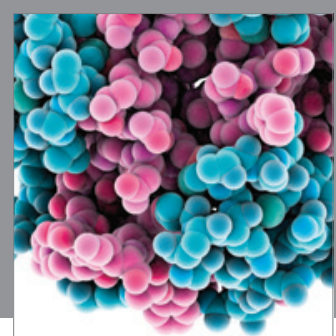

Journal of
Diabetes Research

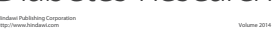

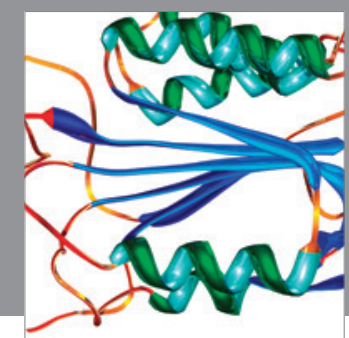

Disease Markers
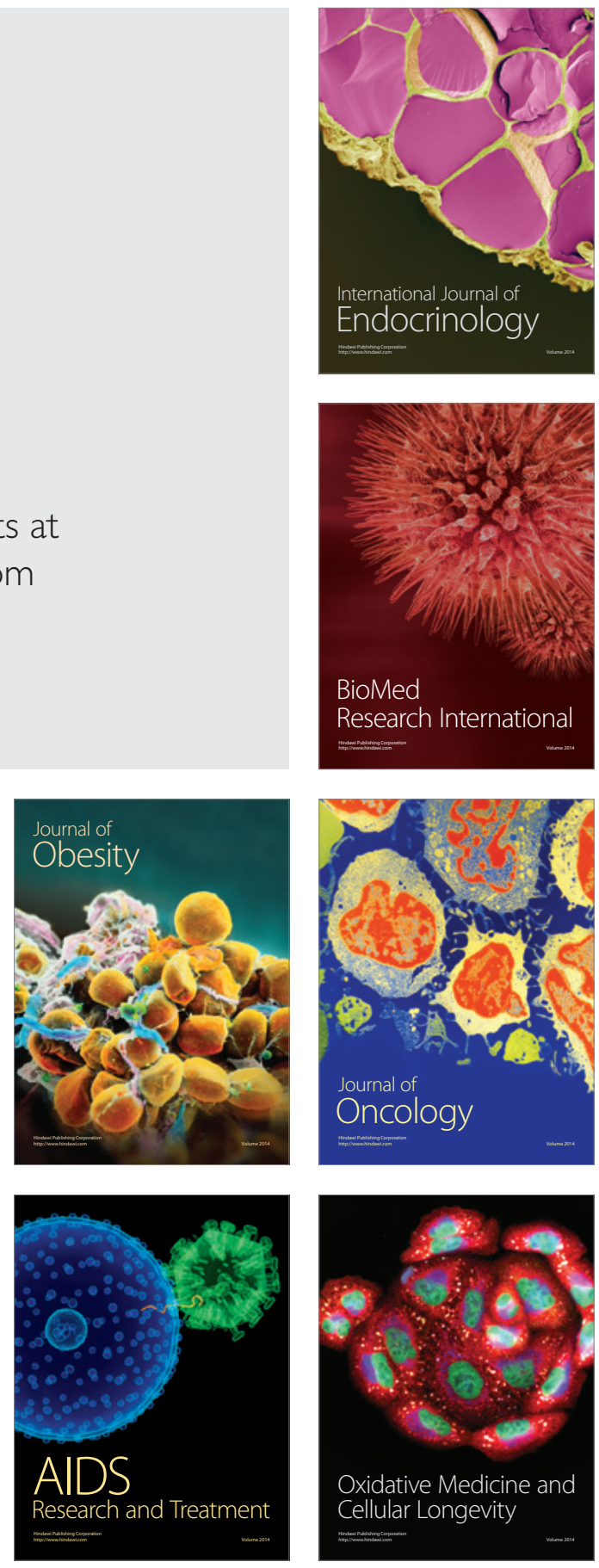